\title{
Bioclimatic Urbanism and Regional Design in Portugal: The Atlantic and the Mediterranean Contexts
}

\author{
Maria Guerreiro $^{1}$ and Israel Guarda ${ }^{2}$ \\ 1. Center for Research and Studies in Sociology, University Institute of Lisbon-Av. Forças Armadas, Lisbon 1649-026, Potugal \\ 2. Institute of Art History, New University of Lisbon-Av. de Berna, Lisbon 1069-061, Potugal
}

\begin{abstract}
The subject of the present work is the study of the relationship between the city shape and its geographical and climatic context. This is a very important feature of the Portuguese city. The Iberian Peninsula comprised by Spain and Portugal belongs to very different environments: the Atlantic and Mediterranean sea. This position is responsible for a series of highly contrasted regions. The external forces presented in each region, influence the shape, location and orientation, not only of individual buildings but of whole villages in such a way that we can identify patterns of construction in different natural regions. There is in fact, a remarkable correspondence between climate and urban type which is useful to identify for planning the different regions. The legacy of industrial city, as in other parts of the world, has changed this close connection between geography and architecture, with consequences not only in environment but especially for the identity of urban spaces. Bioclimatic urbanism is not just a question of sustainability or survival. It is also a question of local identity and variety. There is in fact a relationship between cultural process and environment responsive which we can learn from the structures of the past — the pre-industrial city. We believe that the reinterpretation of the traditional city patterns forms a language which can be used as a design process for recovering urban landscape.
\end{abstract}

Key words: Urban nature regional design, bioclimatic urbanism, environmental response, local identity.

\section{Introduction}

"Nothing is experienced by itself, but always in relation to its surroundings...” [1].

The idea that space itself has a structure which influences the shape of every existing thing may sound strange, since we usually think of space as a kind of nothingness that is the absence of structure. The space has an architecture that makes real demands on things. Every form, every pattern pays a price for its existence by conforming to the structural dictates of space [2]. Form and context are not separated - they form an indivisible whole. Thus, the context is a template for the form and the coherence of the form depends on the degree to which it fits the rest of the ensemble. However, this kind of coherence which is common in vernacular architecture is very difficult reach in design.

Corresponding author: Maria Guerreiro, $\mathrm{PhD}$, research fields: urban morphology, spatial and configurational analysis, complexity and urban science, landscape, ecology. E-mail: rosalia.guerreiro@iscte.pt.
The reason is because in the first case the form generated gives response to one or more problems functionality, while in the latter case the form is not always the solution to its context. As Christopher Alexander says, "The form is the solution to the problem; the context defines the problem. In other words, when we speak of design, the real object of discussion is not the form alone, but the ensemble comprising the form and its context” [3].

The task of design is to create order in the whole, which is reached when the form gives response to the conditions of natural environment, like the orientation of the house to the winds or the sun, the size and location of the openings in accordance with the entry of light, ventilation or heat, etc..

The context which informs the form of a settlement is constituted by all that surrounds the site, including the landscape, be it desert, valley, mountain, forest, seaside, riverside, and what is above the surface, the atmosphere, which contains the humidity on which 
human, animal, and plant life depend. However, according to the idea above, when a building is proposed it changes the context. This is particularly true when we are dealing with bioclimatic aspects: “A principal propose of a building is to change the microclimate. Early men built houses to keep out the elements - rain, wind, sun, and snow. Their purpose was to produce an environment favorable to their comfort and even to their survival. The microclimate of each building site is changed into several different microclimates as the result of the construction of the house itself. The microclimate adjacent to the south wall is quite different from that at the north wall and the climates at the east and west walls are again different” [4]. “Over many centuries, people everywhere appear to have learned to interact with their climate. Climate shapes the rhythm of their lives as well as their habitat and clothes. Thus, they build houses that are more or less satisfactory in providing them with the microclimate that they need”.
Fig. 1 illustrates this relationship between form and context. It shows two different building concepts for cold and hot climates. In Portugal, we can adopt these concepts for Atlantic (Northern region) and for Mediterranean (Southern region) contexts respectively. As a climate response, the center of the composition in cold climates is the fire place while in hot climates the center is the fountain within a patio.

\section{The Unselfconscious Process and the Self-conscious Process of Making Cities}

There are two types of city: The natural cities, those cities that had been formed over time more or less spontaneous and the artificial cities, those that resulted in part or entirely of a plan or design prior. We may distinguish as well, the difference between our own culture, which is very self-conscious about its architecture and certain cultures which are rather unselfconscious about their. "In the unselfconscious culture there is little thought about architecture or design as such. There is a right way to make buildings
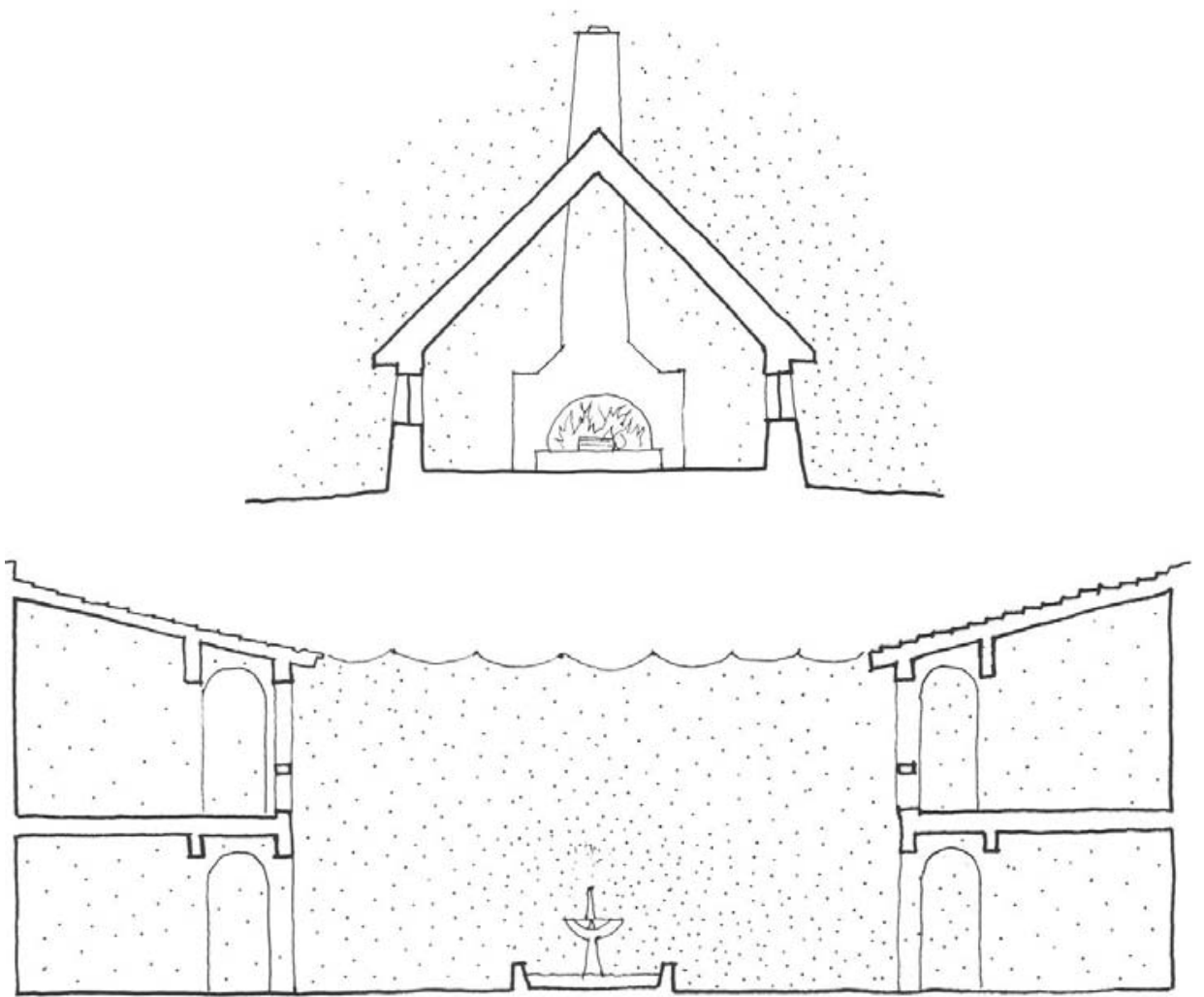

Fig. 1 Cold-climate hearth, hot-climate shaded fountain: The central symbol of thermal comfort [5]. 
and a wrong way, but while there may be generally accepted remedies for specific failures, there are no general principles comparable to Alberti's treatises or Le Corbusier's. Since the division of labor is very limited, specialization of any sort is rare, there are no architects, and each man builds his own house” [3].

We can say that natural cities are those produced by an unselfconscious culture while artificial cities are those produced by a self-conscious culture. Why then, the buildings and the cities produced by an unselfconscious culture are so well fitted in context compared with those produced by a self-conscious culture?

It seems, as pointed by Christopher Alexander, that the unselfconscious form-making process has a structure that makes it homeostatic or self-organized, like many structures in nature, which consistently produces well-fitting forms [3].

We believe that this structure is conducted by natural context and when we are building with nature, responding to climate, topography, etc., we are making this structure self-organized and homeostatic. These successful solutions to the problems of natural context did not result from deliberate scientific reasoning. They grew out of countless experiments and accidents and the experiences of generations of builders who continued to use what worked and rejected what did not [4]. Portuguese traditional settlements are very good examples of self-organized structures conducted by its natural context. Late industrialization and strong rural tradition led to an urbanization of the territory which not erased the traditional structures.

\section{Portugal: The Atlantic and Mediterranean Contexts}

The Portuguese territory is situated at the occidental edge of the Iberian Peninsula where the coast area occupies a big range of the country. In this remoteness two very different environments are presented: maritime and continental. This position is responsible for the highly contrasted regions that oppose north/south and east/west. In addition, the diversity of regions presented results from geological, hypsometrical and hydrographic variety. These conditions responsible for extremes of climate and geography have produced a great variety of dwellings and village forms.

According to the opinion of Portuguese geographers, it is unanimous that Portugal is divided in three great geographical regions: Atlantic Norwest (humid and rainy), Continental Northeast (dry, hot and cold) and south (arid, Mediterranean). It is generally accepted that river Tagus makes the separation between the North regions, with the predominance of high relief and abundance of stone, and the South region, with predominance of plains.

Thus to reach climate comfort in the northern regions it is necessary to minimize the effects of winter, although concerns about the summer are visible, especially in the Northeast region. In the Southern region strategies seek to minimize the effects of a very hot summer.

The external forces presented in each part of the country, have influenced the shape, location and orientation of buildings and villages in such a way that we can identify patterns of construction according to each natural region. Indeed, there is a remarkable correspondence between climate and urban type or house type, which is useful to have present in the environmental planning of each region. This is more and more important as climate change will largely affects Portugal in the future.

In addition to the macroclimate, we have the microclimate as a result of the local conditions, whether by the existence of accentuated topography, vegetation type or water surfaces. More important than regional climate is the context of the site, where the conditions can be very different from the general. In Portuguese latitude, a difference of more than $3^{\circ}$ Celsius of temperature can exist between the north and south slopes [6]. A local breeze or a lake can refresh certain areas in expense of others. An elevation of land 
or a group of trees, which cut predominant winter winds, allows creating more sheltered spaces. These conditions allow man to build better solutions, which improve the general climate of the area.

In the same way, a group of buildings can create a local microclimate which in many cases can improve the general conditions of the site. A good placement, an optimized form, a good balance between the built and empty spaces, as well as the correct placement of vegetation, can improve the building environment face to the general of the area.

Climate and microclimate characteristics are fundamental aspects of traditional structures. The homogenization of architectural and planning styles has lead to the loss of local character produced by an "unselfconscious" culture, which make forms in response to climate.

\section{Built Environment and Bioclimatic Strategies: The Unselfconscious Process}

Because it is a fixed phenomenon, human settlements are pre-eminently a product of geography. However and because it is a phenomenon linked to our life it is almost as ephemeral as ourselves. In the best preserved cities, the older homes have only three or four centuries, in general, the ordinary house disappears and is renewed with great speed. Although it change so quickly, it keeps in its general features, something permanent as a face that conveys which depends to some extent of its natural context [7].

It is mainly vernacular built forms, produced by an unselfconscious cultural process, which better expresses the features of this dependence. We are particularly interested in the dominant type and more representative of each bioclimatic region. We better recognize this dependence in the countryside where life is always more in touch with nature. Building materials, house forms, settlements layout, orientation and location are the aspects that we should look for the differentiation types.

Throughout the world there are a number of cases where the geographical context dependence is surprising: Buildings on stilts in the humid areas or lakes, buried buildings in desert climates or igloos built with snow in Polar Regions are examples of a deep connection between form and context in each geographic region.

In Portugal, from north to south, coast to the interior or mountain to the plain, natural regions succeed and one wonders a regular succession of the current type of settlement. The variety of houses is determined by the nature of the materials - from the stone in its different forms: granite, slate, marble, sandstone, basalt, simple sand and clay, to the wood: pine, oak and brown shirt, all exists in different quantities in each region. In addition, there is the local climate constraints, which are combined with the performed materials producing a right number and size of windows, the existence or nonexistence of the chimney (which in Portugal is very important element in the distinction between north and south), the roof more or less inclined and sometimes asymmetrical to protect from the prevailing wind; the terrace houses, so characteristic of the Mediterranean countries where rainfall is not abundant.

Fig. 2 shows a typical settlement of Lousã Mountains situated at 700 meters of altitude. These mountains like Gerês and Estrela in the North of the country are naturally influenced by the Atlantic Ocean. In these regions the temperature drops with the altitude yielding extreme winters and moderate summers. So, the bioclimatic strategies founded at these regions are related with the passive eating through solar gains. Shading and prevailing winds are avoided. For this reason the settlement are systematically located within the valleys on the south slopes.

In some cases there are seasonal migrations such as the Branda-Inverneira system in Gerês at the Northwest of the country. This system of settlements spread along the valleys in groups of two villages, where people live alternated between summer (at the top of the valley) and winter (at the bottom of the valley).

Villages are settled in amphitheater. The main characteristic of its morphology is that buildings are 


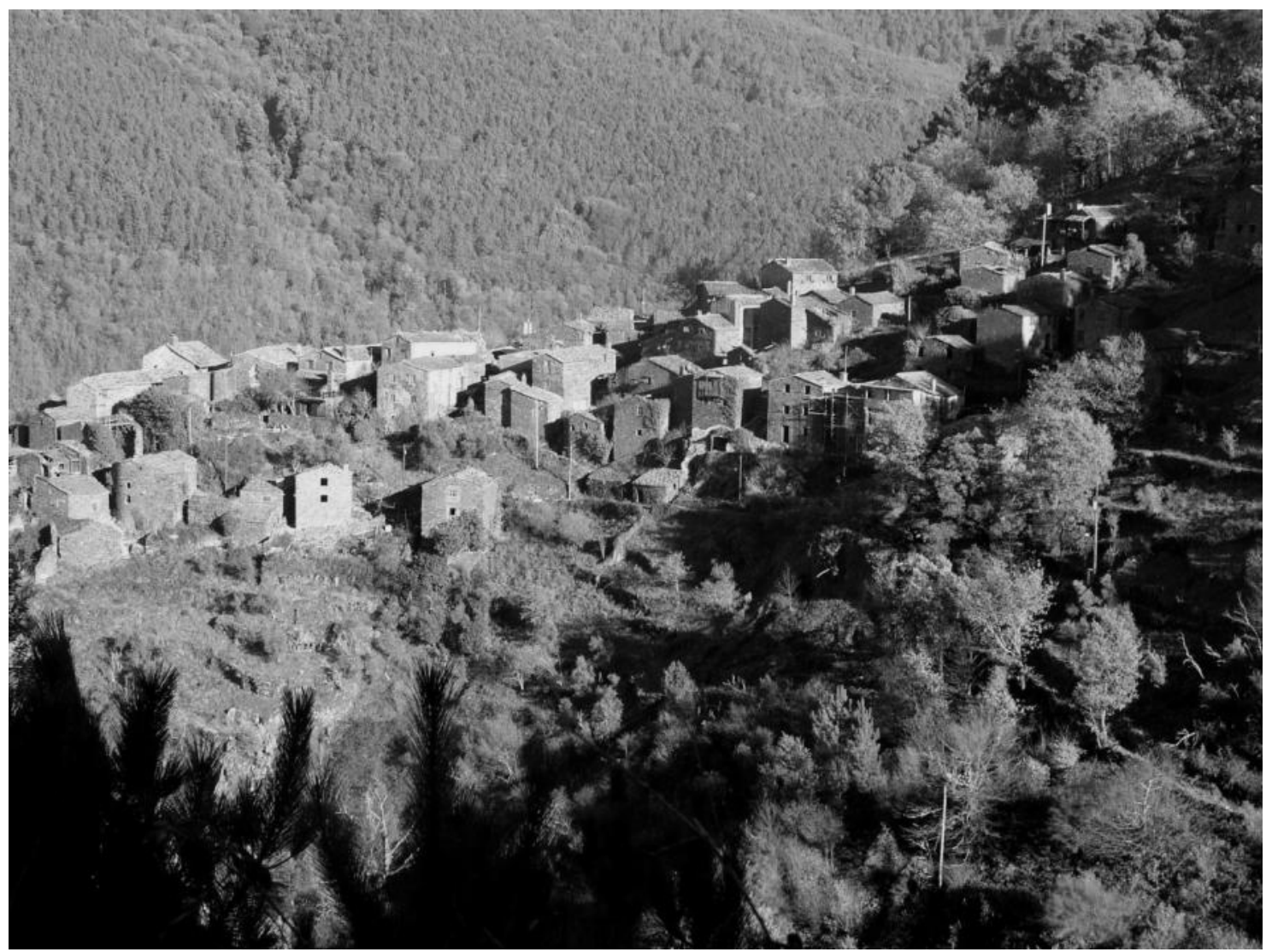

Fig. 2 A typical mountain settlement in the North of Portugal, Talasnal-Lousã.

scattered to catch the sun, given rise to many open spaces that work also as pocket suns. Buildings are settled in compact blocks, composed by two floors with a balcony facing south in upper floor. The scattered morphology is justified by the sun gains but also for a better drainage of the rain, minimizing the effects of humidity and improving urban and building ventilation. For the same reason the pitch roofs are accentuated with big eaves at the side of prevailing winds. According to the natural substrate the building materials, including roofs, are stone, sometimes combined with wood.

Fig. 3 is another excellent example of the relationship between form and context in Atlantic climate. The picture shows a typical fishing settlement at the sea side. However extinct it is relatively recent (about 150 years). The construction is almost exclusively in wood. The extensive forests, the presence of sand and sea come together as factors of a type of architecture closely linked to ecological conditions. The adjustments of these villages to their environment are a good example of climate response of an unselfconscious culture given through the architecture: Wood works correctly in relation to the sandy soil and moisture that the sea air brings.

Unlike the mountain type, the natural substrate of these settlements is very instable and the topography change continuously. With strong winds from the sea and air humidity also very high, the bioclimatic strategies are protection from the winds and the improvement of natural ventilation to avoid moisture.

Sheltered sites like a sand dune increases the protection from the prevailing winds.

In general, the main morphological characteristic of these settlements type is the construction of buildings on stilts, so that the sand can pass under them. The streets are orientated north-south forming elongated blocks in the same direction blocking the sea winds and reduce exposed surfaces to the North. 


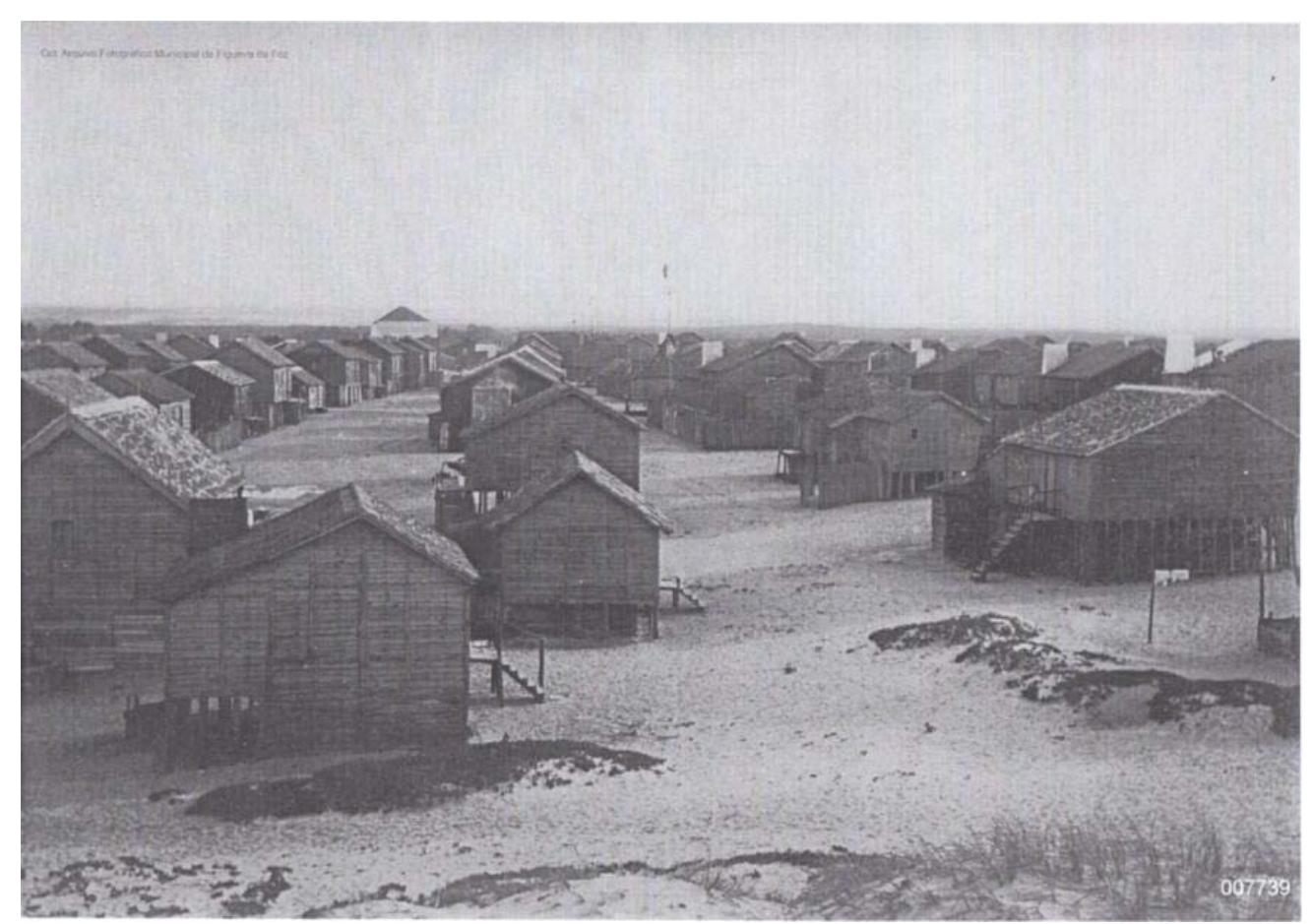

Fig. 3 A typical fishing settlement of Portuguese sea coast, Cova-Figueira da Foz.

Source: Arquivo Fotográfico Municipal da Figueira da Foz.

The buildings are rectangular with one or two floors, elongated in the direction east-west and following the form of the plots. Buildings are set up side by side or with a few intervals forming large sectors that make up the north-south streets, rarely interrupted by east-west streets and thus reducing the area of buildings exposed to the north.

The settlement on the picture (Fig. 3) no longer exists. It was once called the "city of stakes" and its dynamic equilibrium is a perfect example of symbiosis between man and nature - a lesson for the future planning of those areas.

Fig. 4 shows a typical settlement from the south of the country - city of Évora, where the influence of the Mediterranean climate is visible. Stone and wood from the north contrast with the earth materials from the south. Villages are white, compact and settled at the top of the hills to catch the breezes, thus smoothing the effects of very hot summers.

The choice of narrow north-south streets can help shading adjacent spaces or the facades of the buildings east and west that are most critical during the summer.
Other public spaces elongated in the same direction may also have the same effect. As the streets east-west are more difficult to shade in summer and warm in winter the choice for a mesh rotated 45 degrees of the cardinal axes, which Ralph Knowles called the "Spanish grid" [8] allows optimal allocation of sun and shade throughout the year as well as during the day.

This kind of grid is very common in the South of Portugal. The majority of the streets have the orientation NE-SW, which are then interrupted by radial streets that completes the structure like in the city of Évora.

Fig. 5 is another example of architecture as a consequence of climate - city of Olhão. It is one of the southern towns of the country where the influence of the Mediterranean climate is felt more intensely. It is situated next to the sea where the predominant activity was fishing until some years ago. As rainfall is scarce ceilings are terraced, configuring a "cubist village", a term found to define this aspect in view of the cubic clusters that the most popular neighborhoods take. 


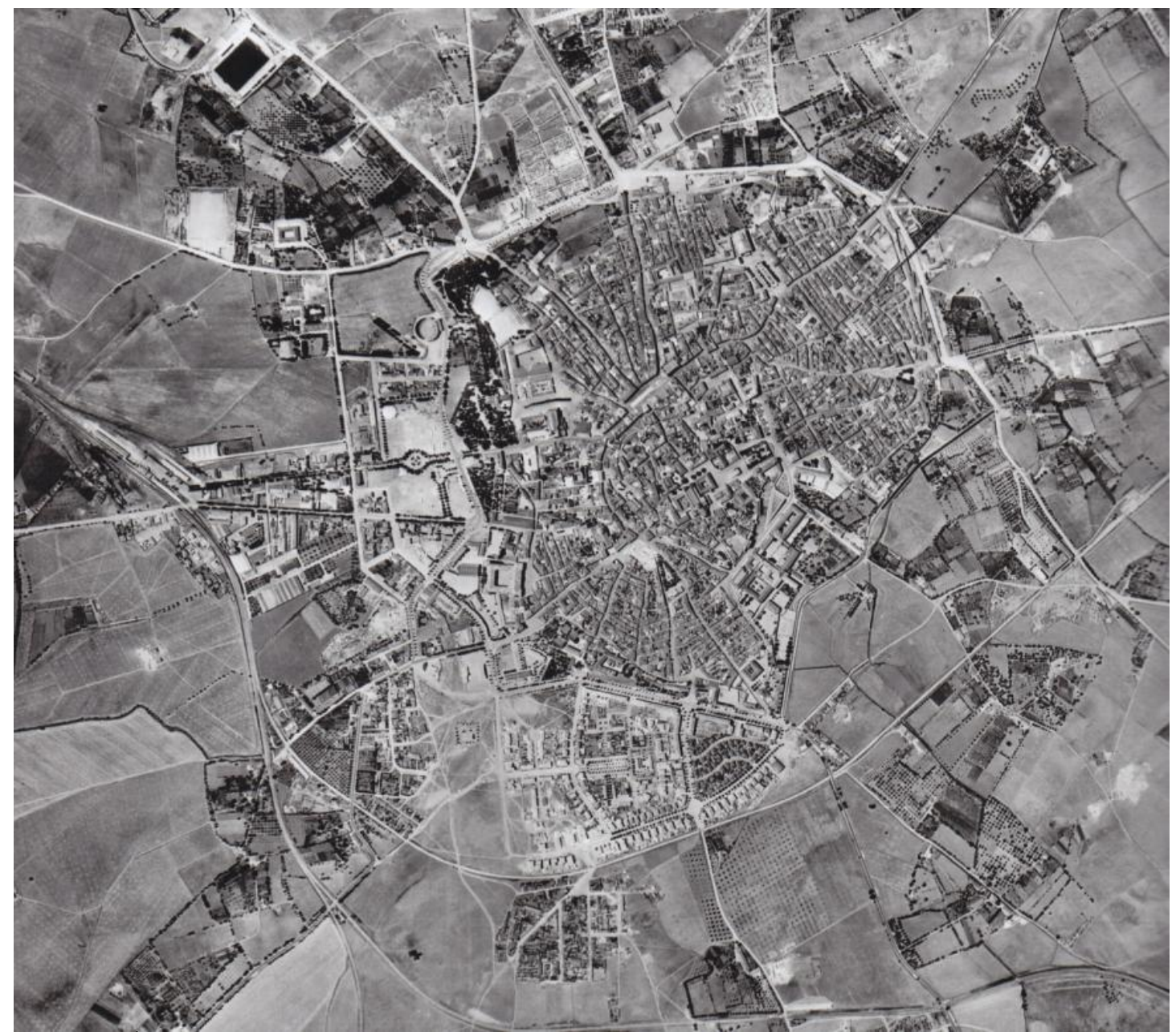

Fig. 4 The city of Évora, a typical street network of the South of Portugal.

Source: Instituto Geográfico do Exército

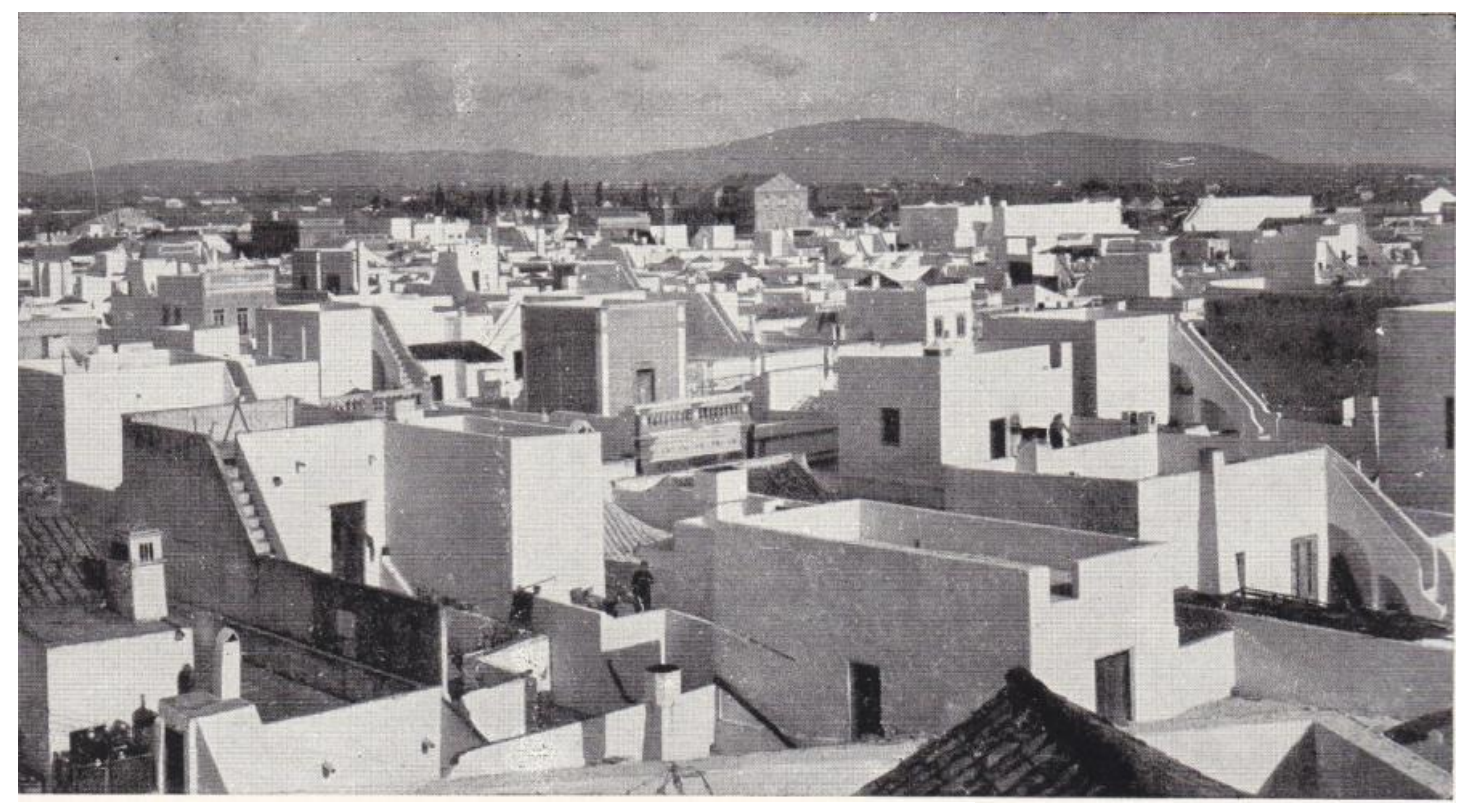

Fig. 5 The city of Olhão, a typical fishing settlement of the South of Portugal [9]. 
As it looks like a North African village, the first explanation for this urban morphology is the survival of a Moorish occupation. Although the Moorish left the South of Portugal at the end of the XIII century and the village just have had its origins at the XVIII century. Of course, the modern town of Olhão is a copy of Moroccan cities with which its inhabitants remained profitable business relationships. However it was the climate which allowed such copy.

\section{Regional Design Experiences: The Self-conscious Process}

Aspects of adaptation to climate must influence the architectural design not only in its style or small changes but in its essence and conceptual framework: the project must be embedded in climate concerns from the first phase of the creative process of the architect.

This relationship involving context and design was experienced among the Portuguese architects, especially after the realization of the vernacular architecture inquiry. This study published in 1961 under the title, "Portuguese Popular Architecture", was of great significance, because it helped to change a single view of Portuguese house.

This approach, besides the interest of confronting the "unified idea" of a Portuguese House released by the government dictatorship, intended to discuss the great variety of building throughout the country, strongly influenced by the geographical conditions of each region. In addition this study was very important to create a dialogue between vernacular and erudite architecture which influences the architecture produced during 1950s and 1960s in Portugal.

This discussion was remarkably important in the context of post second Great War, related with a critical review of the rationalist architecture of the modern avant-garde. Probably the most important actor of this turning point was Alvar Aalto. His work is directed to aspects as the built environment, climate and the local traditions - a close and more sensitive relation with the place which Kenneth Frampton defined as Critical
Regionalism [10]. By other words, Nezar Al Sayyad put it in this terms: "Critical Regionalism designated a form of architectural practice that embraces modern architecture critically for its universal unifying qualities while simultaneously respond to social, cultural, and climatic context on the region in which it is to be built" [11].

To illustrate the influence of the vernacular on contemporary Portuguese architecture, we present two design examples to illustrate the dichotomy between Atlantic-Mediterranean contexts.

Fig. 6 shows the Atlantic example from the architects [12] for a rural area at the extreme Northeast of the country. The project proposes a new community out of a group of buildings distributed along a valley and occupying the two shores of a small river.

To identify the design problems and their solutions, the authors make an analysis of the implementation of existing settlements in the surroundings to justify their options. Between the relationship of regional and contemporary elements are the considerations of climate.

In this region where the winter is very cold and the summer is very hot, the choice for the site is critical. At 800 meters of altitude, valleys are more favorable then the ridges exposed to the regional winds. However the bottom of the valleys is avoided because it is very hot in the summer and very cold in winter. Thus the slopes are the most favorable sites.

The north-south elongated houses are grouped side by side along the valley. They are oriented east-west, thereby exposing the lower section to the North. The architecture reproduces the traditional block house in stone with two floors and a balcony for solar gains in winter and shading in summer. The chimney is in the center of the composition as it is typical in a cold climate.

Finally, Fig. 7 shows the Mediterranean example, from the architect Álvaro Siza Vieira, for an extension of the city of Évora, where was planned a number of large towers. Siza Vieira was asked to make a project 


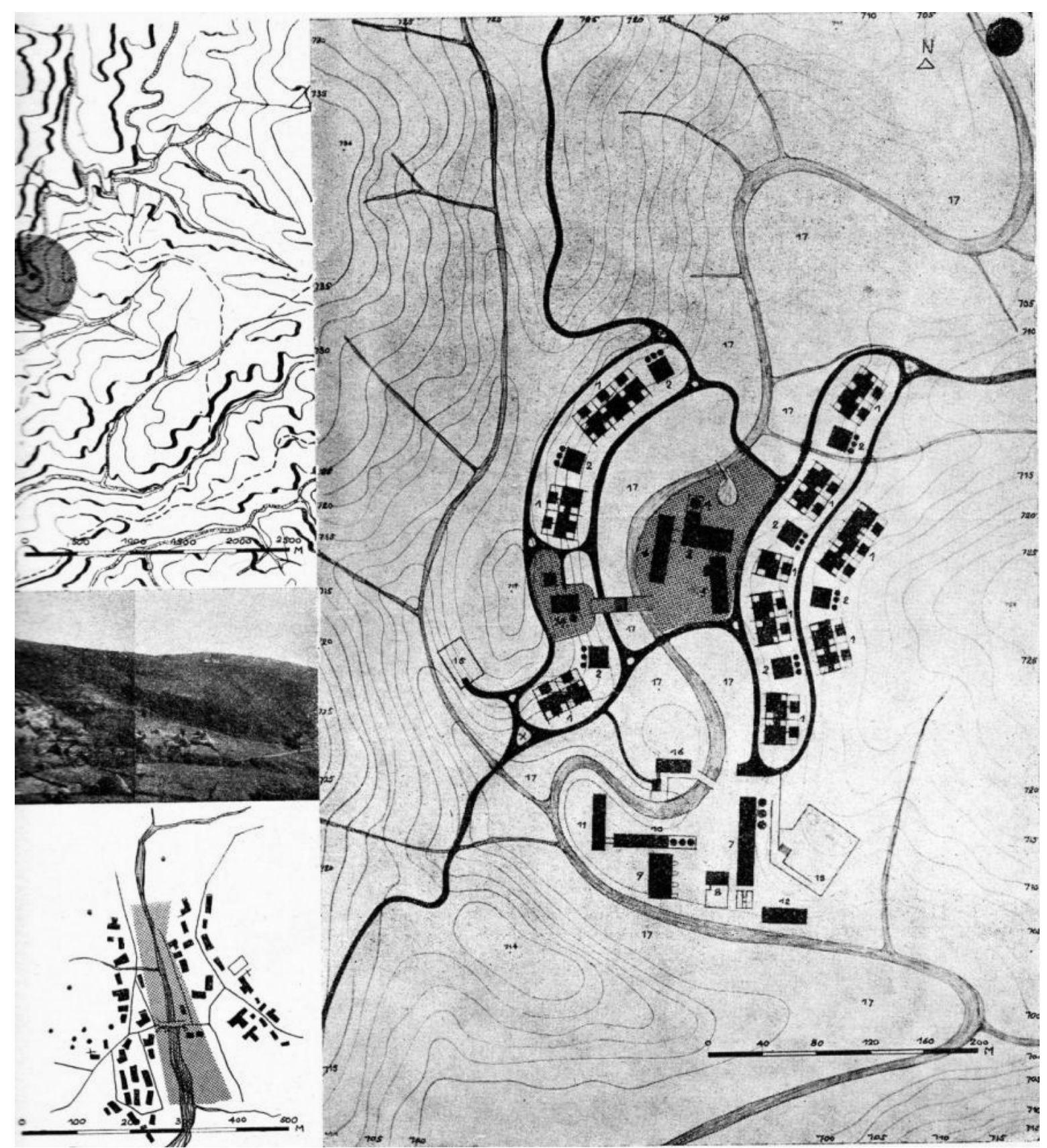

Fig. 6 Project for a rural area at the extreme Northeast of Portugal, from the architects Viana de Lima, Fernando Távora e O. Figueiras [12].

more sensitive with the city and its environmental context. The adoption of elongated blocks almost north-south with the houses back-to-back, set up in submission to the topography and the pre-existences, contribute to the unity and variety of formal set.

Comparing with the first example the density of this project is higher, following the typical compactness of Mediterranean cities, the streets have almost north-south orientation and the patio is the centre of the composition of the house, as it is typical in hot arid climates.

Both examples require the adoption of designs appropriate to local conditions, thereby eliminating the possibility of settling on universal or international designs for buildings that must be used in all countries and climates. 


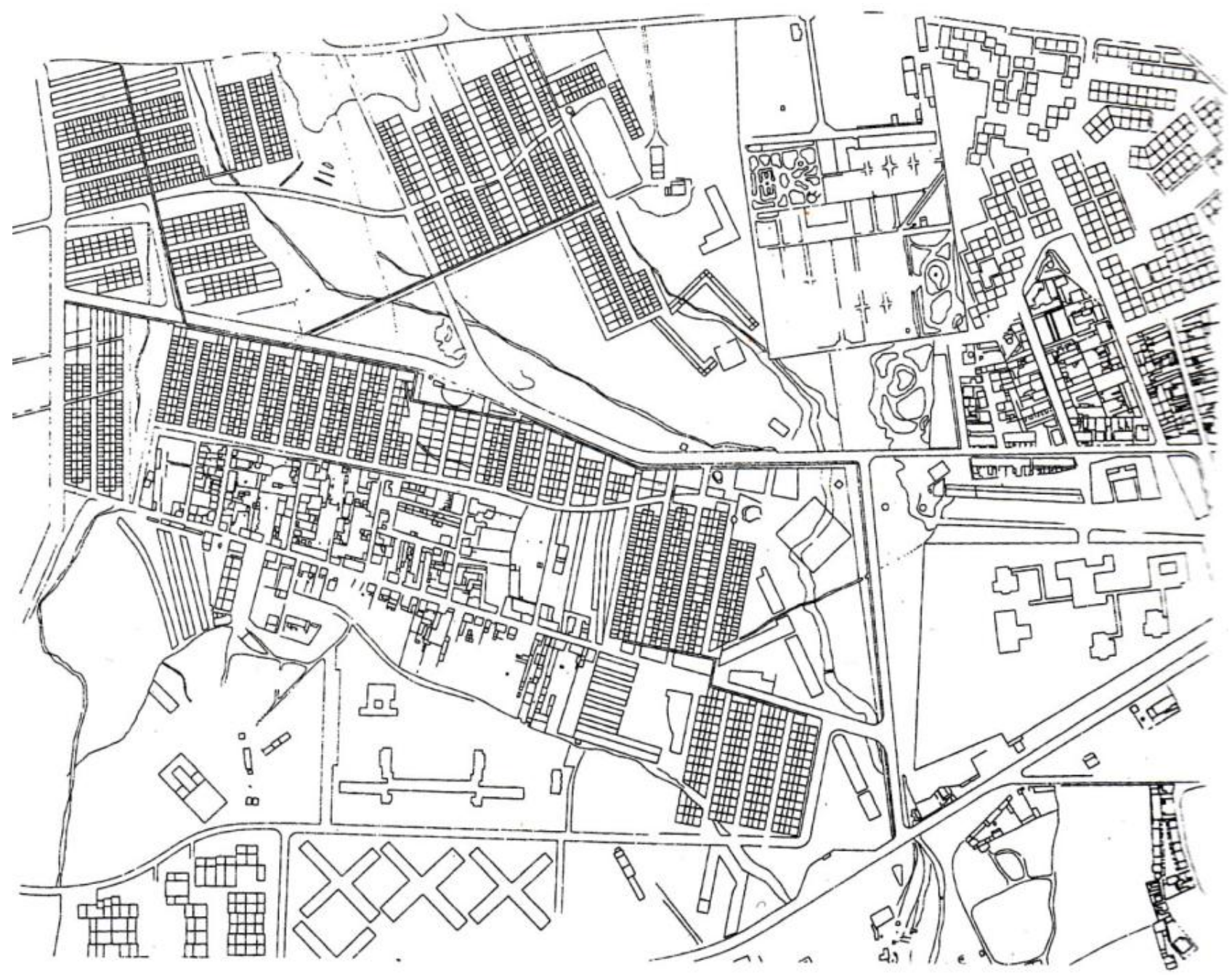

Fig. 7 General view of the Malagueira Neighborhood, Évora, a project from the architect Álvaro Siza Vieira [13].

\section{Conclusions}

According to the idea that form and context are not separated, this work has found a remarkable correspondence between climate and urban type in Portuguese traditional settlements. The external forces presented in each region, influences the shape, location and orientation of buildings in such a way that the whole villages emerge within a structure that makes it homeostatic and sustainable.

This conclusion is of major importance regarding bioclimatic urbanism planning process in nowadays. It is clear from the above that architecture which meets the context depends upon maintaining a high level of critical self-consciousness. It may find its governing inspiration in such things as climate and geography used in the past in a peculiar structural mode by an unselfconscious culture.

\section{References}

[1] K. Lynch, The Image of the City, Massachusets Institute of Tecnology, Massachussets, 1960, p. 11.

[2] P. Stevens, Patterns in Nature, An Atlantic Monthly Press Book, Boston, 1974, p. 4.

[3] C. Alexander, Notes on the Synthesis of Form, Harvard University Press, Cambridge, 1964.

[4] H. Fathy, Natural Energy and Vernacular Architecture, Principles and Examples with Reference to Hot Arid Climates, The University of Chicago Press, Chicago, 1986, p. 7.

[5] J. Reynolds, Courtyards, John Wiley \& Sons, New York, 2002. 
[6] R. Serra, Architecture and Climates, Editorial Gustavo Gili, Barcelona, 1999, p. 10.

[7] J. Brunhes, Geografia Humana, Editorial Juventud, Barcelona, 1995, p. 48.

[8] R. L. Knowles, The Solar Envelope, available online at: http://www-rcf.usc.edu/ rknowles/sol_env/sol_env.html.

[9] A. Girão, Geography of Portugal, Portucalense Editora, Porto, 1951. (in Portuguese)

[10] K. Frampton, Towards a critical regionalism: Six points for an architecture of resistance, in: H. Foster (ed.), Postmodern Culture, Pluto Press, London, 1985, pp. 16-30.
[11] N. Al Sayyad, Foreword: On the study of "regional architecture”, in: W. M. Kingstom, Heath Vernacular Architecture and Regional Design Cultural Process and Environmental Response, Architectural Press, Oxford, 2009, p. XI.

[12] V. Lima, F. Távora and O. Filgueiras, Arquitectura, in: Proceedings of X Congress of CIAM, Lisbon, Jan.-Feb. 1959, pp. 21-28. (in Portuguese)

[13] La Arquitectura del Espacio Público, Junta de Andalucia, 1999, p. 82. 